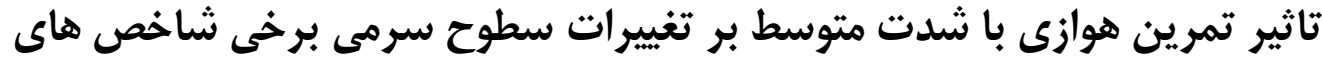

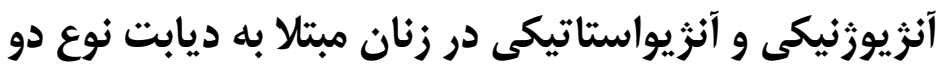

\author{
اكسير ويزوارى'، بروين فرزانكى '، هاجر عباس زاده صورتى' \\ ا) كروه فيزيولوراثى ورزشى، دانشكده علوم (نسانى، ولحد سارى، دانشكاه آزاد (سلامى، سارى، إيرانغ.
}

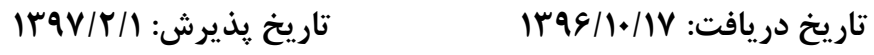

\begin{abstract}
جيكيده

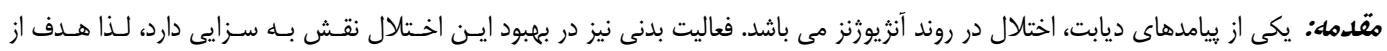

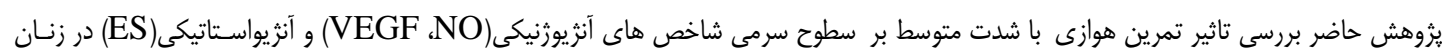
مبتلا به ديابت نوع دو بود.

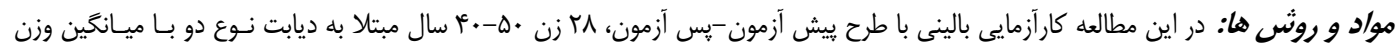

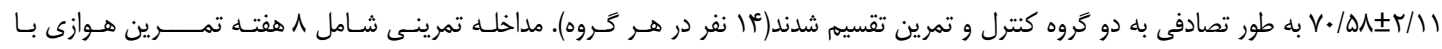

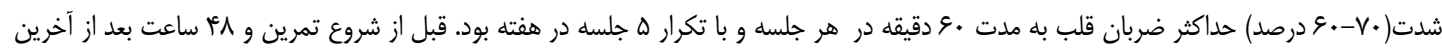

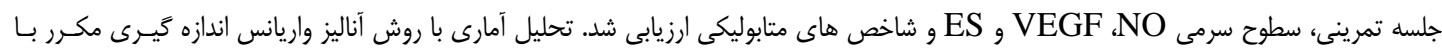

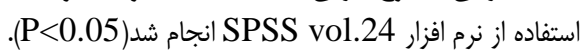

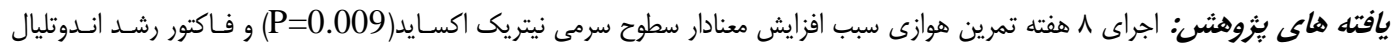

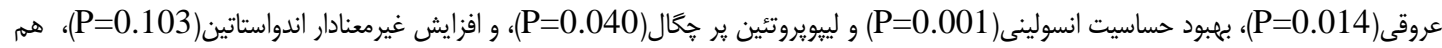

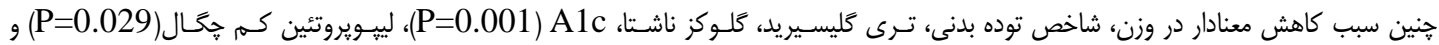

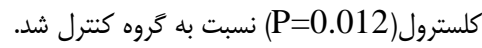

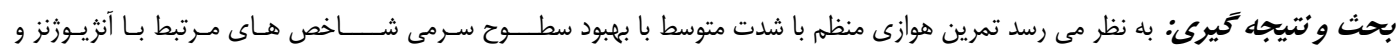

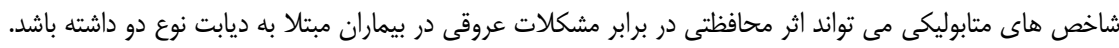

وازه هاى كليدى: ديابت نوع ז، نيتريك اكسايد، فاكتور رشد اندوتليال عروقى، اندواستاتين، يروفايل هربى، تمرين

* نويسنده مسئول: كروه فيزيولورثى ورزشى، دانشكده علوم انسانى، واحد سارى، دانشحاه آزاد اسلامى، سارى، ايران Email: parvinfarzanegi@gmail.com

Copyright () 2019 Journal of Ilam University of Medical Science. This is an open-access article distributed under the terms of the Creative Commons Attribution international 4.0 International License (https://creativecommons.org/licenses/by-nc/4.0/) which permits copy and redistribute the material, in any medium or format, provided the original work is properly cited. 
و فاكتور رشد اندوتليوم عروقى (NO= Nitric Oxide) $(\mathrm{VEGF}=$ Vascular Endothelial Growth اشاره نمود كه توليد و فعاليت زيستى آن ها Factor ) در ديابت كاهش مى يابد(1). NO مولكولى تنظيمى با ليا

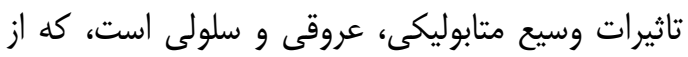

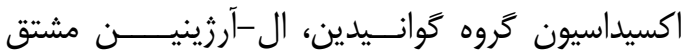
مى شود و عامل اتساع عروقى است و تقريباً در تمام

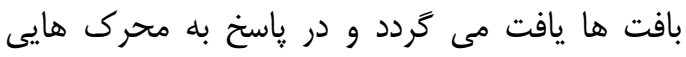
مانند هاييوكسى در بافت و تنش برشى سلول

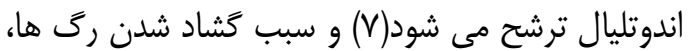

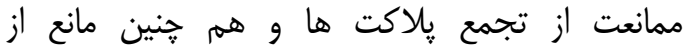

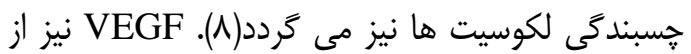

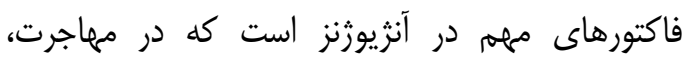
تكثير، تجزيه ماتريكس سلول هاى اندوتليال، تشكيل شبكه هاى عروقى و هم خنين توليد NO و آزادسازى

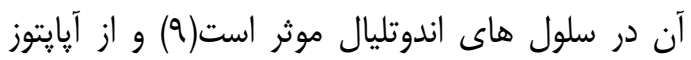

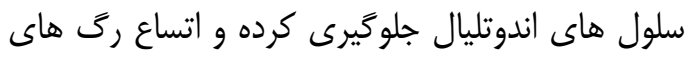
خونى را نيز تنظيم مى كند(•). از محرى هاى آن آن

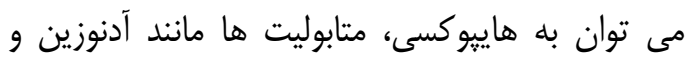

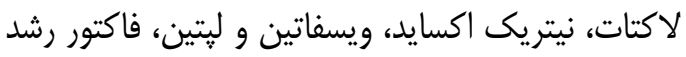

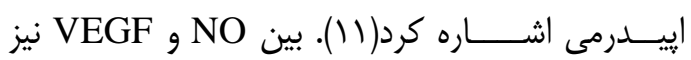
عملكرد متقابل وجود دارد •(1). بر اساس شواهد تجربى، توانايى براى ترميم بافت از طريق آنزيوزنز، كه نياز به

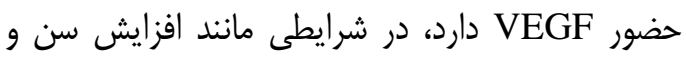
ديابت دجار اختلال مى شود( (I).

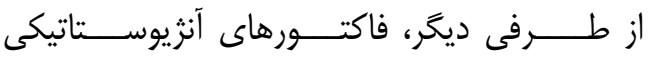

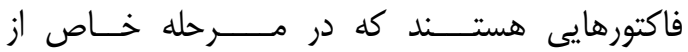
فر آيند آنزيوزنز وارد عمل شده و مانع از فر آيند آنزيوزنز

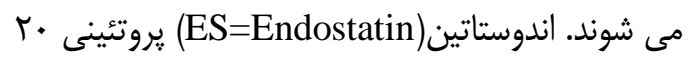

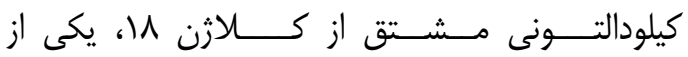
مهار كننده هاى آنـــــزيوزنز است كه توسط ماتريكس خارج سلولى شامل متالو ماتريكس يروتئاز، كاتسبين ها

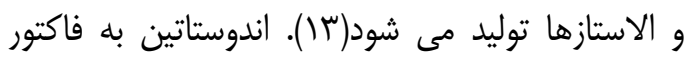

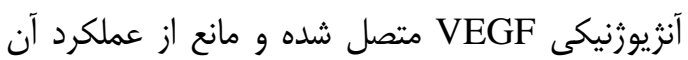

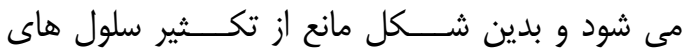
اندوتليال مى شود. هم جنين مانع از تخريب غشاى

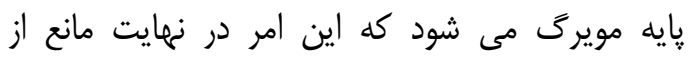

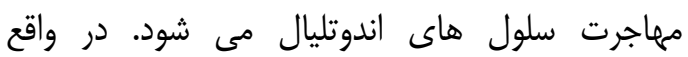

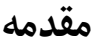

ديابت و ديغر بيمارى هاى مزمن، حاصل كاهش فعاليت بدنى ناشى از تغيير در سبك زندگى است. ديابت مليتوس، بيمارى مزمن متابوليكى است كه با سطح بالاى كلوكز خون و ترشح ناكافى يا اختلال

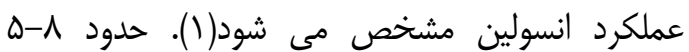
درصد بزرگسالان در دنيا و حدود \| درصد جمعيت كل

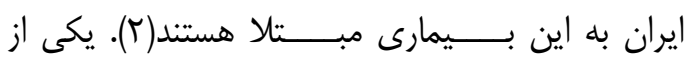

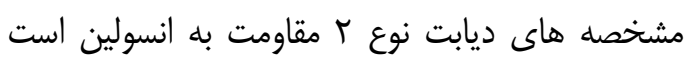
كه به نظر مى رسد علاوه بر اختلال در متابوليسم كلوكز، سبب اختلال در عملكرد اندوتليال از طريق

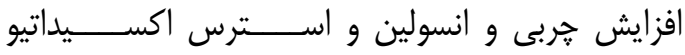

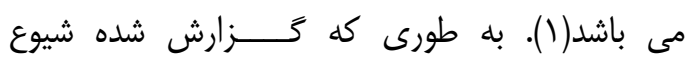
بيمارى هاى قلبى عروقى در افراد ديابتى نسبت به جمعيت عمومى بالاتر است(ّا). ديابت با آترواسكلروز ييش رونده مرتبط مى باشد. از عواملى كه در ايجاد

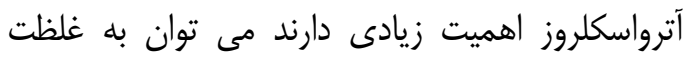

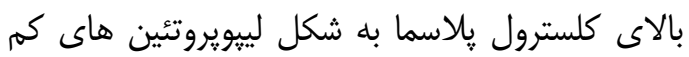
جֶًال اشاره كرد. شاخص هايى مانند لييويروتئين هاى كم קحال، ترى گليسيريد، كلسترول، در افراد ديابتى

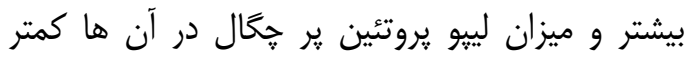
است(ا). اين بيمارى هم جنين با بسيارى از تظاهرات بالينى در افراد ديابتى مانند نقص در ترميم زخهم، ناهنجارى هاى جنينى در مادران ديابتى و اختلال در درابن

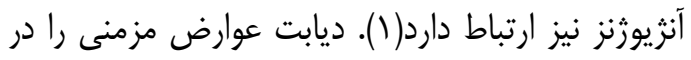

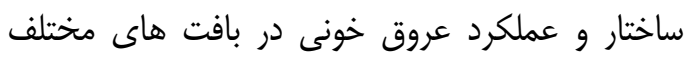
بلن به همراه دارد كه اين عوارض در عروق كوخى درى

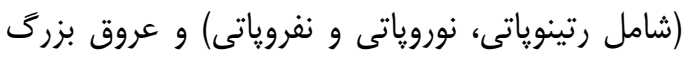
(شامل بيمارى عروق محيطى و بيمارى قلبى عروقى)

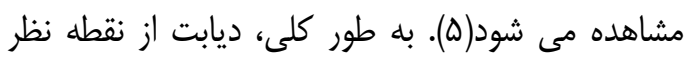

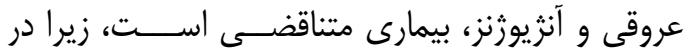

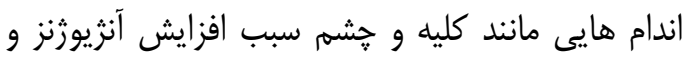
در قلب و عروق محيطى موجب مهار آن مى شود. لذا

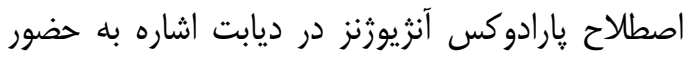

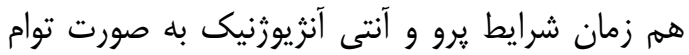
در اين بيمارى دارد(ع). فاكتورهاى متعددى در تحريك آنــــريوزنز دخيل مى باشند كه از آن ها مى توان به نيتريك دريك اكسايد 
آمارى اين يزوهش را بيماران زن ديابتى نـوع r سـاكن

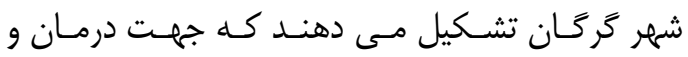

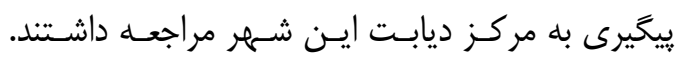

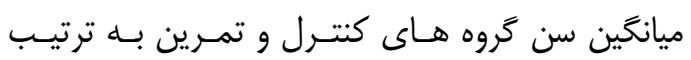

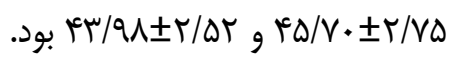

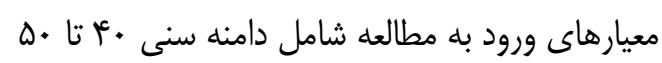
سال، قند ناشتاى بيش از وبا ميلى گرم بر دسى ليتـر،

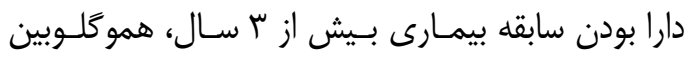

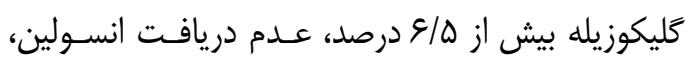

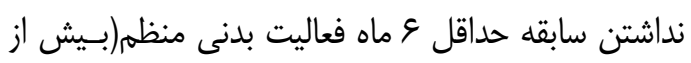

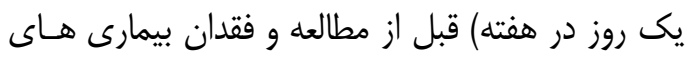

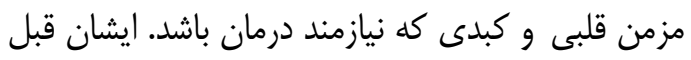

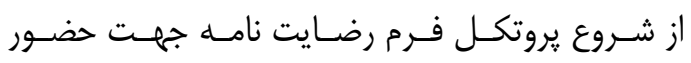
داوطلبانه را نيز تكميل و امضاء كردند. از ايشان خواسته رئه

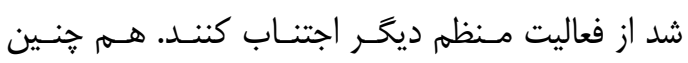

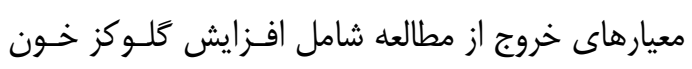

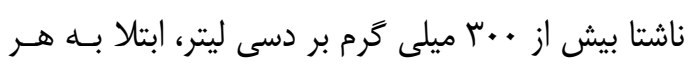

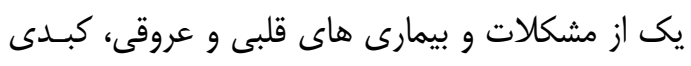

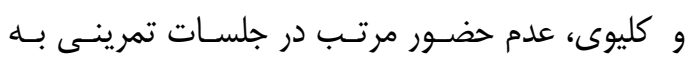

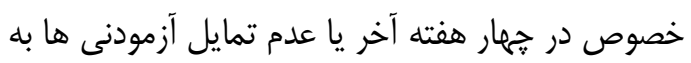

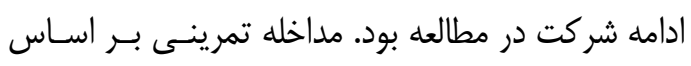

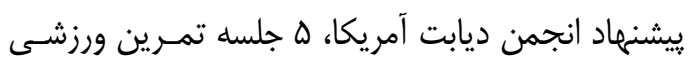

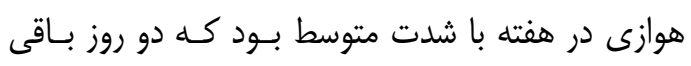

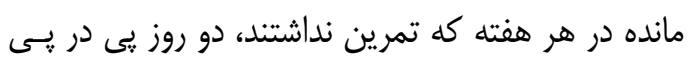

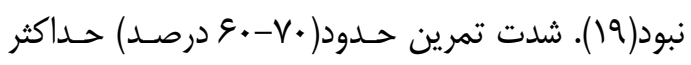

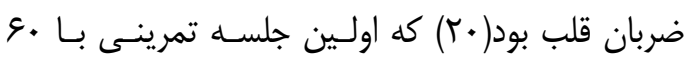

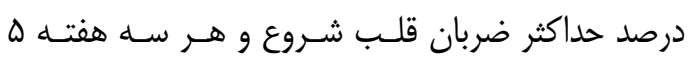

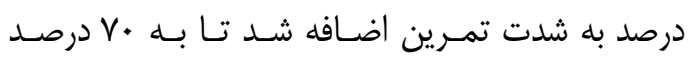
حداكثر ضربان قلب رسيد و به همان منوال ادامـه داده

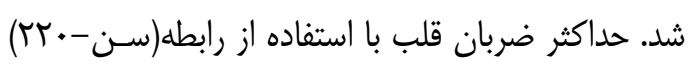

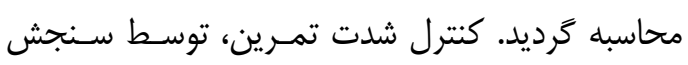

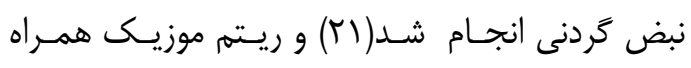

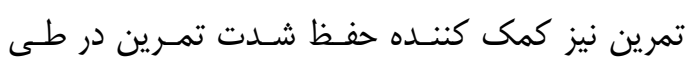

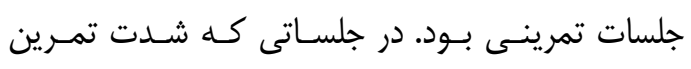

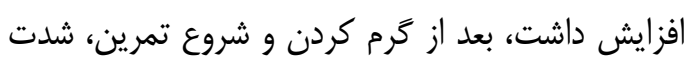

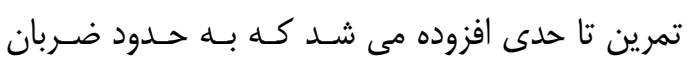

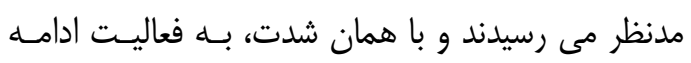

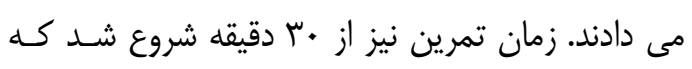

اندوستاتين با ممانعت از تكثير و مهاجرت سلول هاى اندوتليال مانعى براى رشد شبكه مويرگى مى باشداند (1). در بدن انسان متعاقب تمرينات ورزشى تغييرات

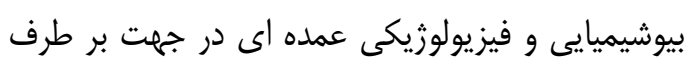
ساختن شرايط استرسى ناشى از فعاليت ورزشى و بهبود

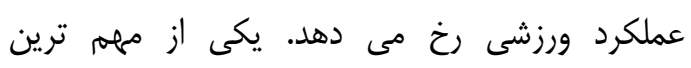

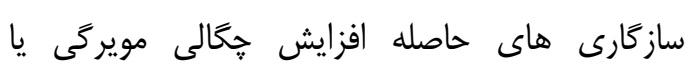
آنزيوزنز است كه از طريق افزايش تنش برشى اصنى ناشى ازي

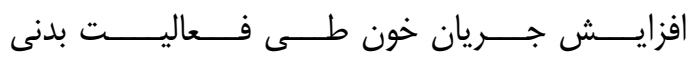

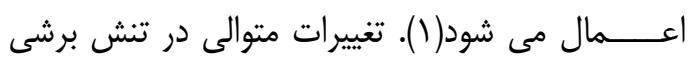

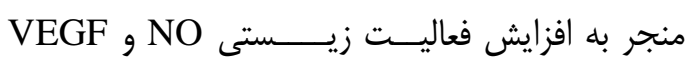

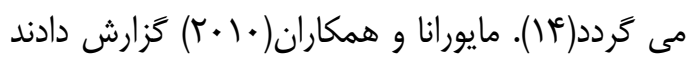
تمرينات تركيبى هوازى و مقاومتى سبب افزايش پاسخ

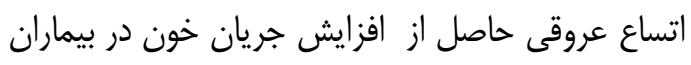

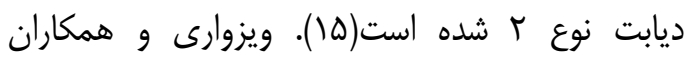

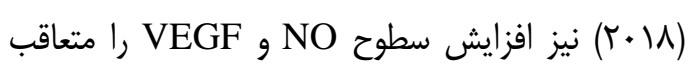
هشت هفته تمرين هوازى در زنان ديابتى ززارش

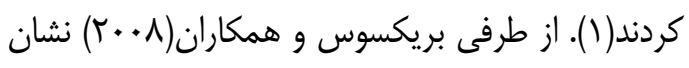

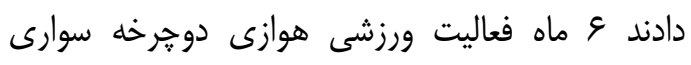

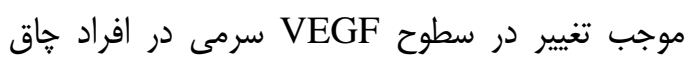

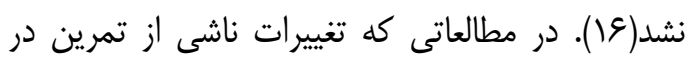

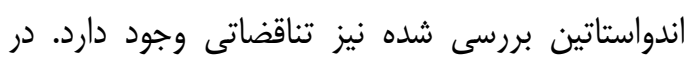

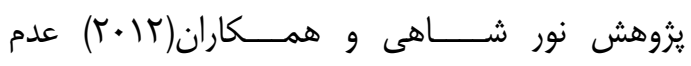

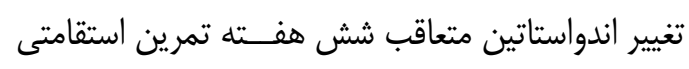

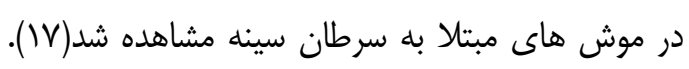

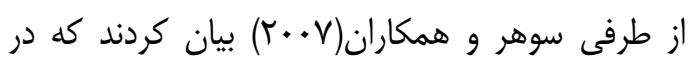

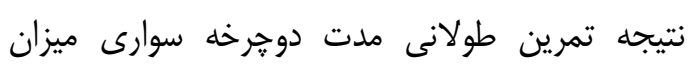

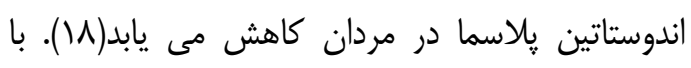
توجه به اهميت اين شاخص ها و عملكرد آن ها و نين بانيز

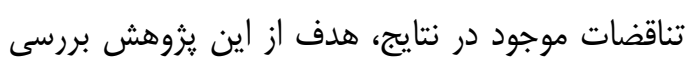
تاثير تمرين هوازى با شدت متوسط بر تغييرات سطوح سرمى برخى شاخص هاى مهارى و تحريكى آنزيوزنز در زنان مبتلا به ديابت نوع دو بود.

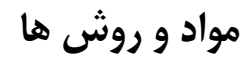

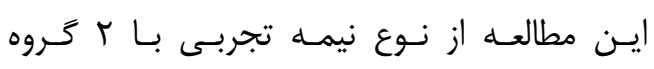

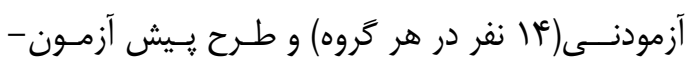

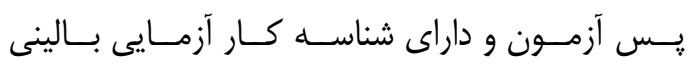
(IRCT20171104037225N1) 


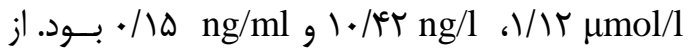
آمار توصيفى جهت توصيف داده ها استفاده شد و تمـام داده ها به صورت ميانخين همراه با انحر اف معيـار بيـان

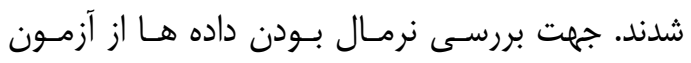

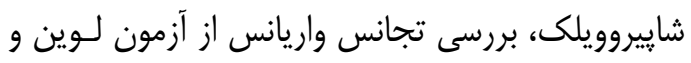

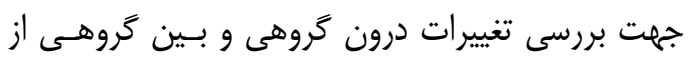

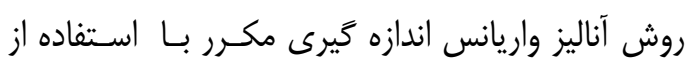

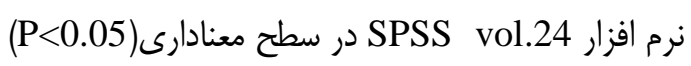

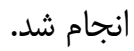

\section{يافته هاى يزوهش إنش}

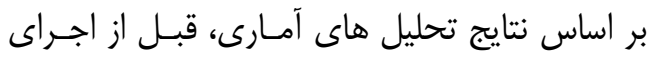

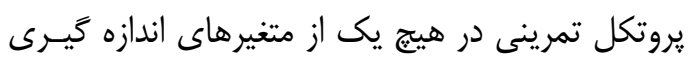

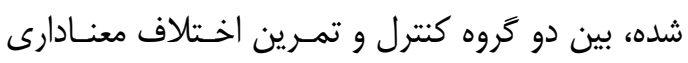

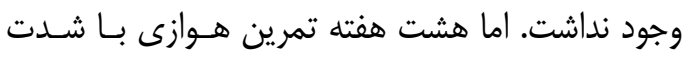

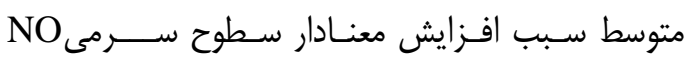

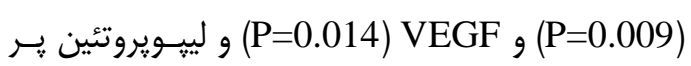

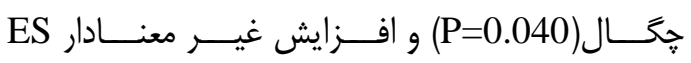

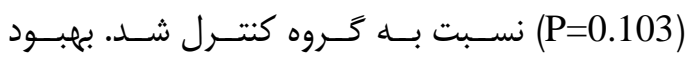

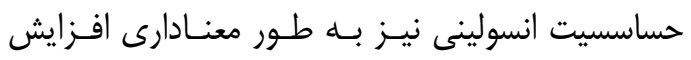
داشته است(P=0.001). مداخله تمرينى هم جنين سبب كاهش معنــادار وزن،

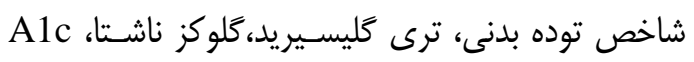

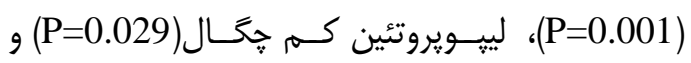

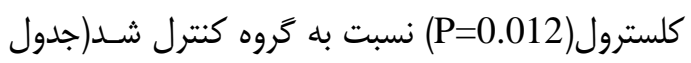

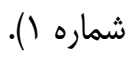

هر جلسه ا دقيقه به زمان تمرين افزوده شد تادر پايان

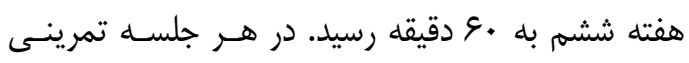

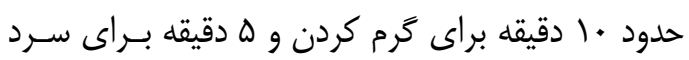

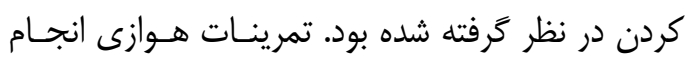

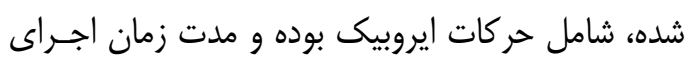

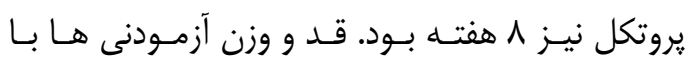

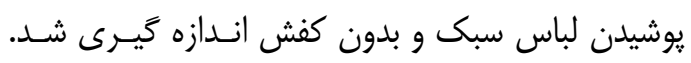

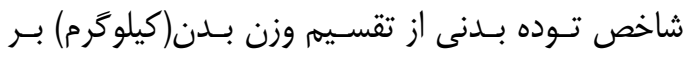

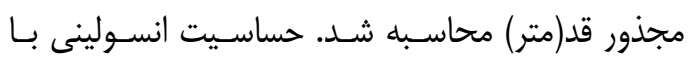
شاخص QUICKI نيز با استفاده از فرمول زير محاسبه كرديد(باشת). QUICKI $=1 /[\log ($ fasting insulin $(\mu \mathrm{U} / \mathrm{ml})$ ) $+\log$ (fasting glucose( $\mathrm{mg} / \mathrm{dl})$ )]

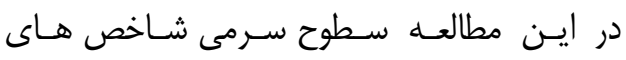

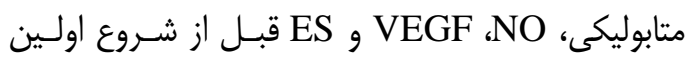

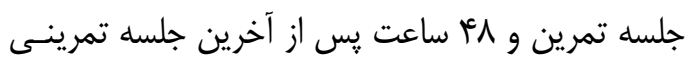

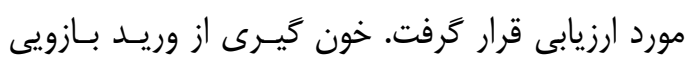

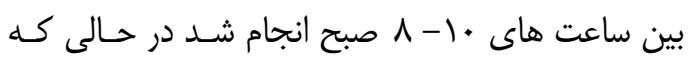

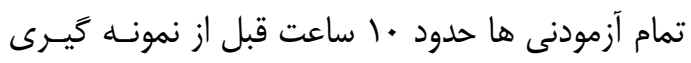

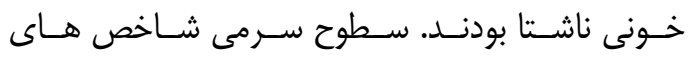

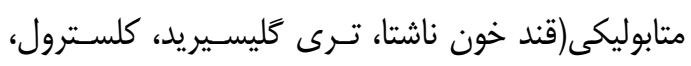

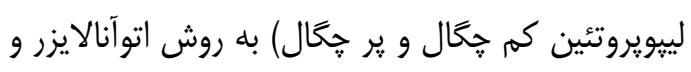

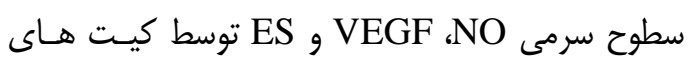
تهيه شـده از شـركت EASTBIOPHARM سطع سـاخت

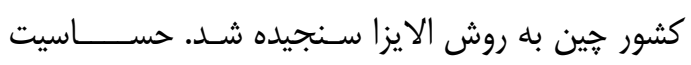

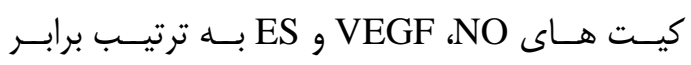




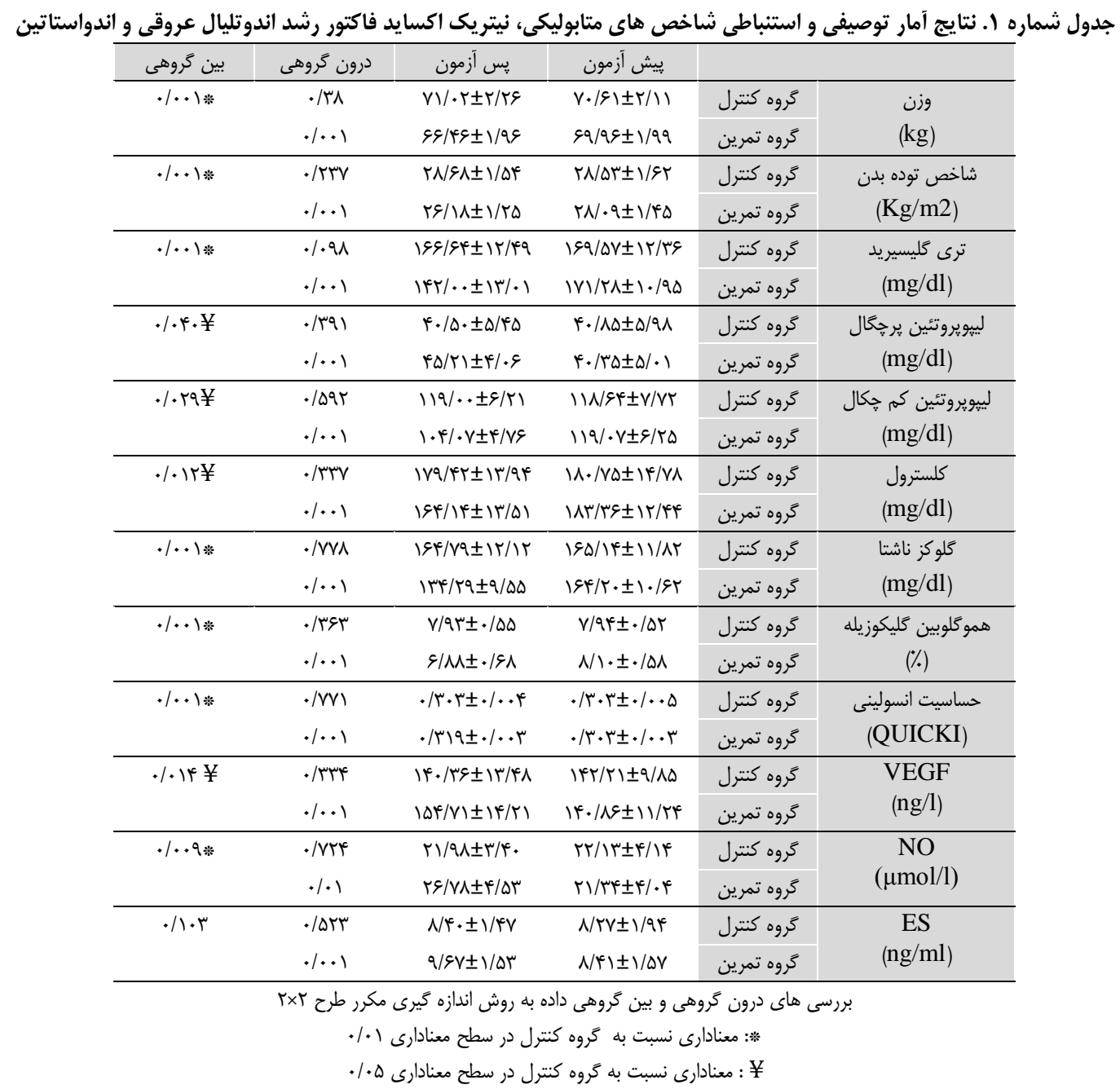

متابوليسم قند، جربى و مقاومت انسولينى مى شود كه سبب كاهش عوارض بيمارى ديابت مى شود(سآ). هم

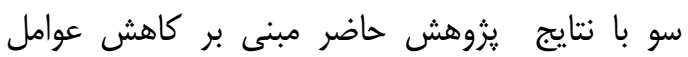
خطــــرزاى قلبى عروقى متعاقب فعاليت بدنى منظمه، ويزوارى و همكاران(1) · (T) نيز كاهش معنادار كلوكز

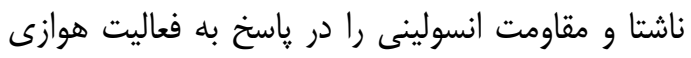

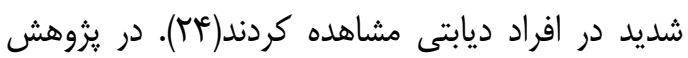
حاضر نيز بهبود حساسيت انسولينى مشاهده شد كه از مكانيزم هاى درگير مى توان به مواردى مانند افزايش

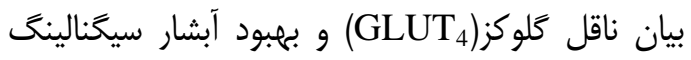

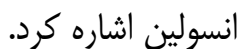

در اين يزوهش 1 هفته تمرين هوازى با شدت متوسط سبب افزايش معنادار سطوح سرمى NO و

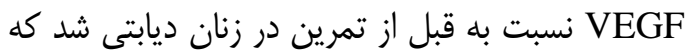

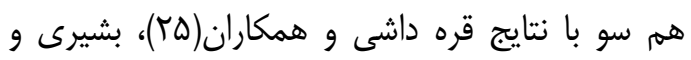

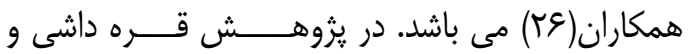

بحث و نتيجه كَيرى

در اين مطالعه اثر هشت هفته تمرين هوازى با ديا شدت متوسط و تكرار ه جلـسه در هفته، بر تغييرات شاخص هاى متابوليكى و سطوح سرمى VEGF NO و ES در زنان مبتلا به ديابت نوع دو بررسى شد. نتايج نشان دادند كه مداخله تمرينى سبب كاهش معنادار در

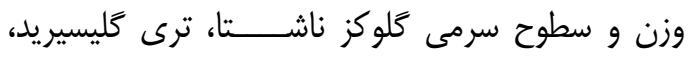

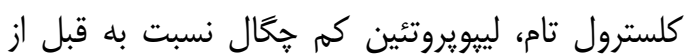

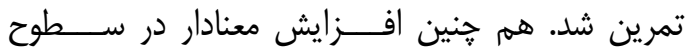

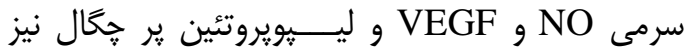
مشاهده شد. سطوح سرمى ES مقدار ناجيزى افزايش داشت كه اين افزايش، معنادار نبود. اختلالات لييبدى در شرايط ديـــابت مــــشاهده مى شود به طورى كه شيوع بيمارى هاى قلبى و

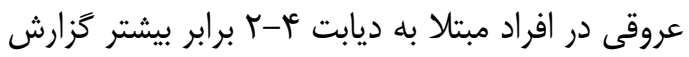

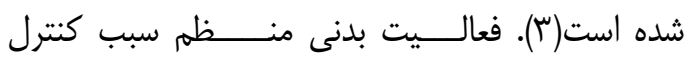


در بيان نيتريك اكسايد سنتاز اندوتليومى بهبود بخشد كه از طريق افزايش دفاع آنتى اكسيدانى مانند افزايش

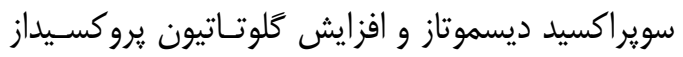

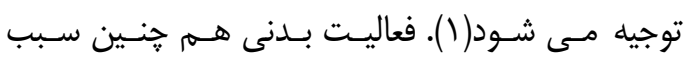

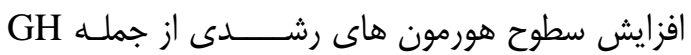
مى شود كه به تبع آن فعال سازى محسور

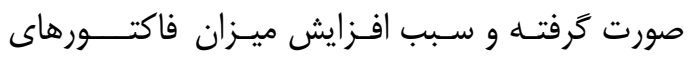

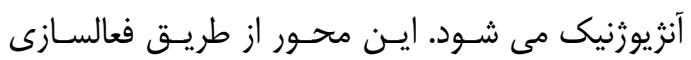

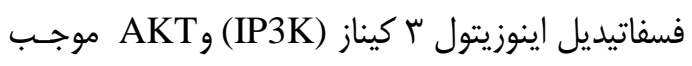
افزايش فاكتور القاءكننده هييوكسى(HIF) مى شود كـــ

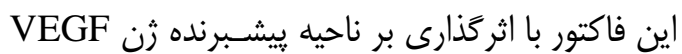

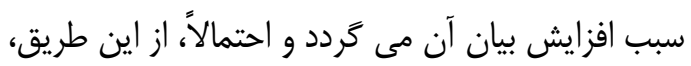

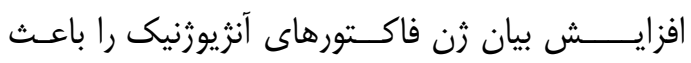

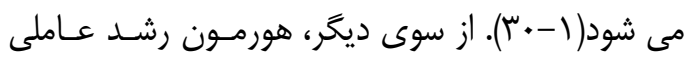

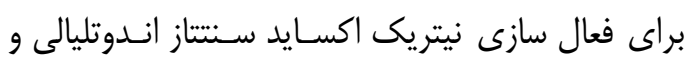
توليد NO است كه اين مسير نيز مى تواند عاملى براى

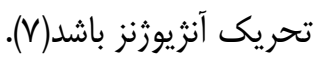

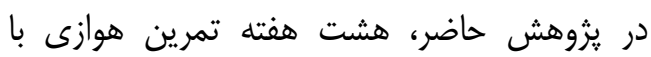

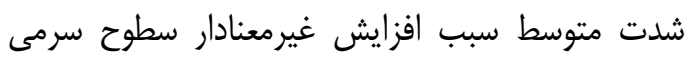

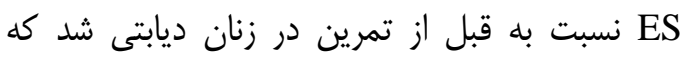

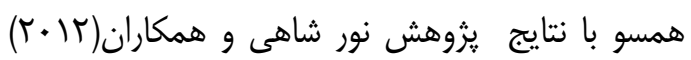

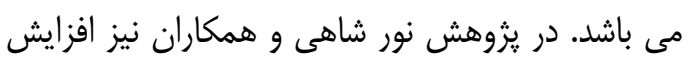

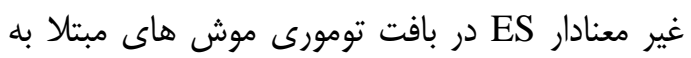

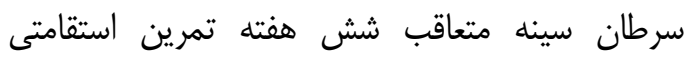

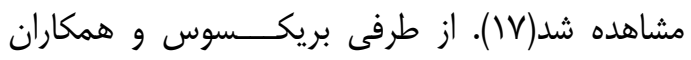

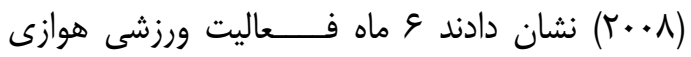
دوجرخه سوارى موجب كاهش معنادار در سطوح سرمى

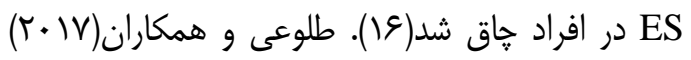

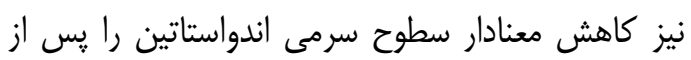

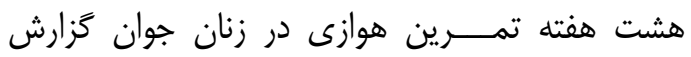
دادند(اس). تحقيقات مختلف نتايج متناقصى را كرازش

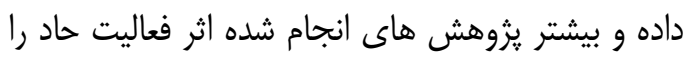
بر تغييرات ES مورد مطالعه قرار داده اند، لذا تاثير

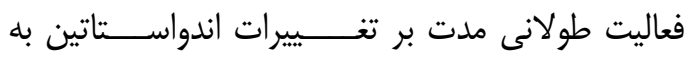

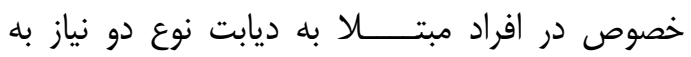
مطالعات بيشتر دارد.

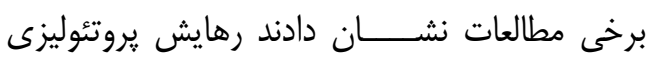

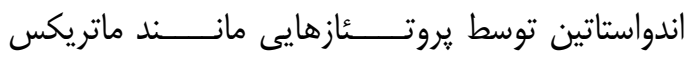

همكاران(Y(+ץ)، ده هفته تمرين تناوبى سبب افزايش سطوح سرمى NO در زنان مبتلا به ديابت نوع دو شد.

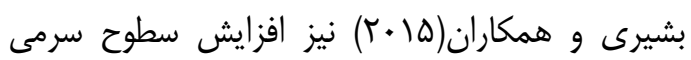

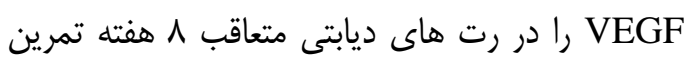

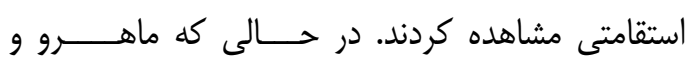

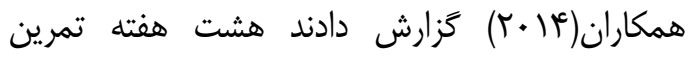

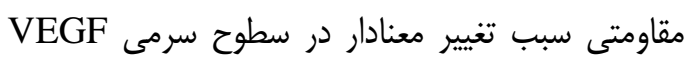

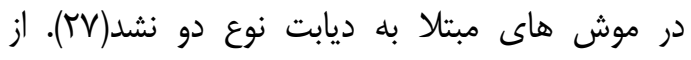

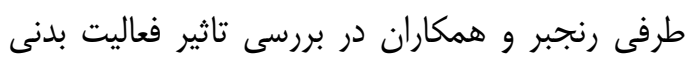

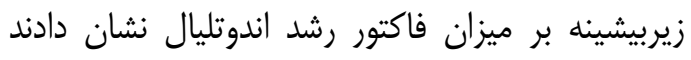

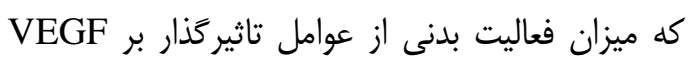

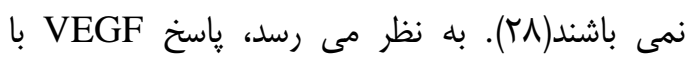

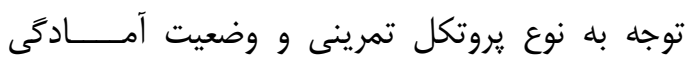
آزمودنى ها متفاوت است.

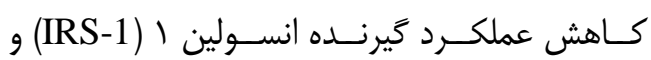

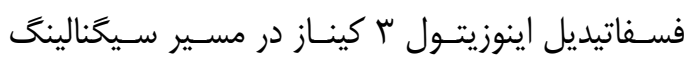

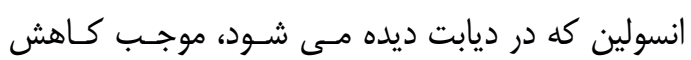

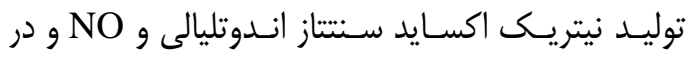

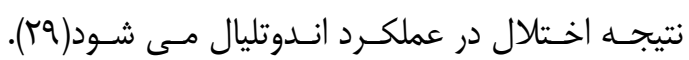

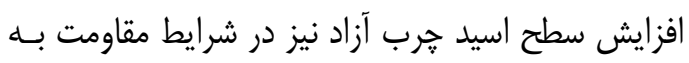

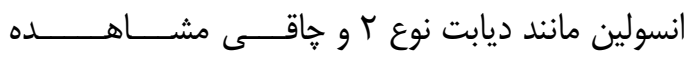

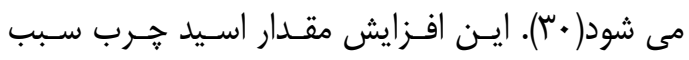

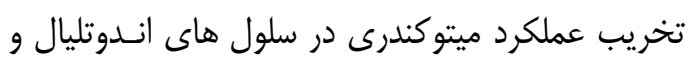

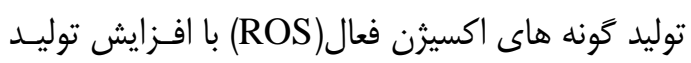

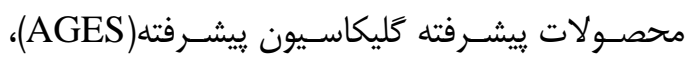

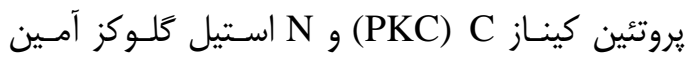
و كاهش فعاليت نيتريـك اكسـايد سـنتناز

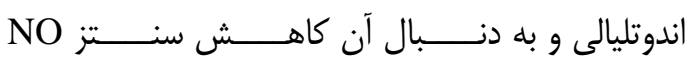

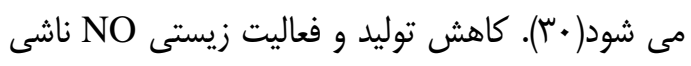

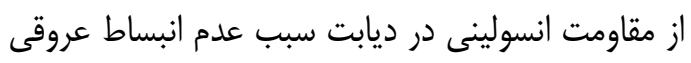

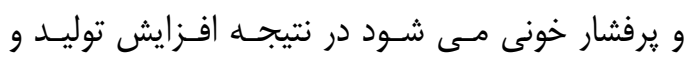

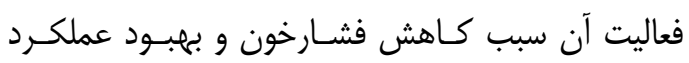

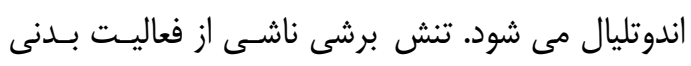

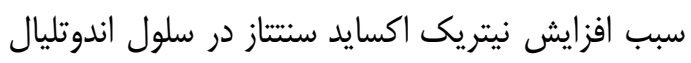
مى شود كه NOS آزادشده از سلول با كمى كميلكس موجب تبديل ال-آرثنين به ال-سيترولين

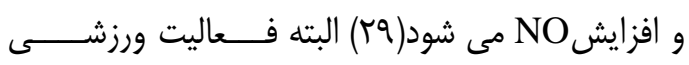
مى تواند اتساع عروق وابسته به NO ما را بـدون افـزايش 


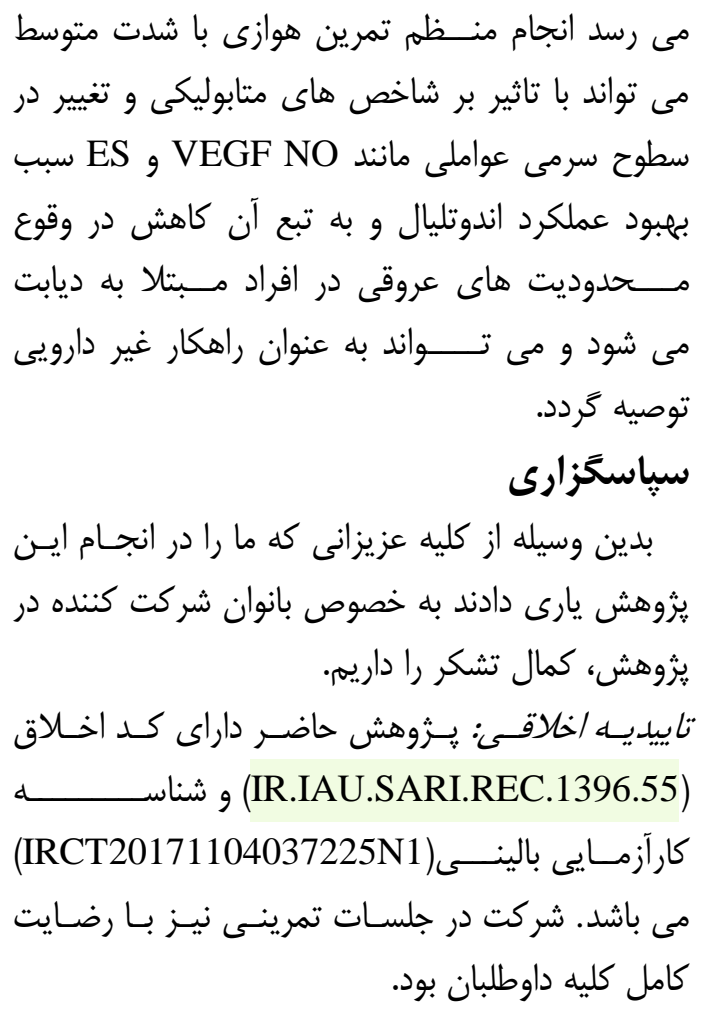

\section{References}

1. Vizvari E, Farzanegi P, Abbas Zade Sourati H. [Effect of vigorous aerobic training on serum levels of some inhibitory and excitatory factors of angiogenesis in Women with type 2 diabetes]. MJMS2018;21:125-31. (Persian) doi: journals.modares.ac.ir/article-30-16360-

fa.htm

2.Lotfi MH, Saadati H, Afzali M. [Prevalence of diabetes in people aged $\geq 30$ years the results of screen-ing program of Yazd ProvinceIran in 2012]. J Res Health Sci 2013;14: 88-92 (Persian).

3.White A, McKay GA, Fisher M. Drugs for diabetes part 9 prescribing for patients with cardiac disease. Br J Cardiol 2012; 19: 85-9. doi:10.5837/bjc.2012.017

4.Chang YC, Chuang LM. The role of oxidative stress in the pathogenesis of type 2 diabetes: from molecular mechanism to clinical implication. Am J Transl Res 2010; 2: 316-31.

5. Kantharidis P, Bo W, Rosemarie M, Carew, Hui Yaolan. Diabetes complications the microrna perspective. Diabetes 2011; 60: 1832-7. doi: 10.2337/db11-0082

6. Salehi E, Khazaei M, Rashidi B, Haghjooye Javanmard Sh. [Effect of

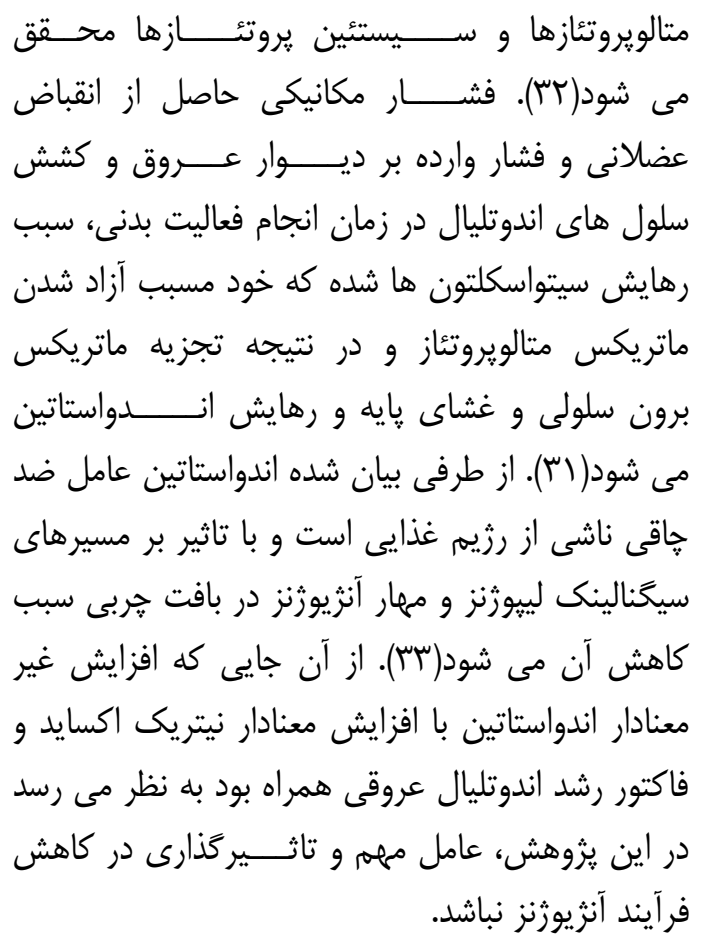

rosiglitazone on coronary angiogenesis in diabetic and control Rats]. J Isfahan Med Sch 2011;29:386-93 (Persian).

7. Mehri Alvar Y, Sayevand Z, Erfaniadab F, Heydarimoghadam R, Samavatsharif MA, Karami S. [The effects of five weeks resistance training on some vascular growth factors in sedentary Men]. Sport Physiol 2016; 8: 15-30 (Persian).

8. Jalali Z, Dabidiroshan V. The effect of regular endurance exercises and galbanum supplement on vascular function during chronic hypertension in male wistar Rats. Sport Biosci 2014; 6: 95-113 (Persian).

9.Salehi E, Amjadi FS, Khazaei M. [Angiogenesis in hea lth and disease role of vascular endothelial growth factor]. J Isfahan Med Sch 2011; 29: 213-226 (Persian). doi:10.1590/S000427302011000200002

10. Mahrou M, Abbas Gaeini, Javidi M, Chobbineh S. [Changes in stimulating in stimulating factors of angiogenesis, induced by progressive resistance training in diabetic Rats]. Iranian J Diabetes Metab 2014; $\quad 14: \quad 1-8$ (Persian). doi://ijdld.tums.ac.ir/article-15314-en.htm 
11. Taherichadorneshin $\mathrm{H}$, Ranjbar $\mathrm{K}$, Nourshahi MA. [Review of response of angiogenic and angiostatic factors to exercise]. Horizon Med Sci 2017; 23: 331-8 (Persian). doi: hms.gmu.ac.ir/article-12588-fa.htm

12. Ferrari G, Cook D, Terushkin V, Pintucci G, Mignatti P. Transforming growth factor-BETA 1 (TGF- $\beta 1$ ) induced angiogenesis through vascular endothelial growth factor mediated apaptosis. J Cell Physiol 2009; 219: 449-58. doi:10.1002/jcp.21706

13.Abdollahi A, Hlatky L, Huber PE. Endostatin the logic of anti angiogenic thera. Drug Resis Upd 2005, 8:59-74. doi: 10.1016/j.drup.2005.03.001 14.Green DJ, Spence A, Halliwill JR, Cable NT, Thijssen DH. Exercise and vascular adaptation in asymptomatic humans. Exp Physiol 2011; 96: 57-70. doi:10.1113/expphysiol.2009.048694

15.Maiorana A, Odriscoll G, Cheetham C, Dembo L, Stanton K, Goodman C. The effect of combined aerobic and resistance exercise training on vascular function in type 2 diabetes. J Am Coll Cardiol 2001; 38: 860-6. doi: 10.1016/S07351097(01)01439-5

16. Brixius K, Schoenberger S, Ladage D, Knigge H, Falkowski G, Hellmich M, et al. Long-term endurance exercise decreases antiangiogenic endostatin signalling in overweight men aged 50- 60 years. Br J Sports Med 2008; 42: 126-9. doi:10.1136/bjsm.2007.035188

17. Nourshahi M, Ghasemi BM, Ayyub B, Zoheyr HFS. [Effect of six weeks continuous aerobic training on tumoral tissue expression of vascular endothelial growth factor and endostatin in Mice with breast cancer]. J Tabriz Uni Med Sci 2012; 34: 82-89. (Persian)

18.Suhr F, Brixius K, de Marees M, Bolck B, Kleinoder H, Achtzehn S, Bloch W, Mester J. Effects of short-term vibration and hypoxia during highintensity cycling exercise on circulating levels of angiogenic regulators in humans. J Appl Physiol 2007; 103:

474-83.

doi:10.1152/japplphysiol.01160.2006

19. Colberg Sh, Sigal R, Yardly J, Riddell M, dunstan D, Demosey P, et al. Physical activity exercise and diabetes a position statement of the american diabetes association. Diabetes Care 2016; 39: 206579.

20. Akbari Kamrani AA, Shams A, Abdoli B, Shamsipour Dehkordi P. The effect of low and moderate intensity aerobic exercise on self-concept in older adults. Iranian $\mathrm{J} \mathrm{Ag}$ 2015; 10: 188-95.

21. Mollazadehesfanjani R, Arazi H, Rohi S, Mohammadi SM. [Effects of aerobic training on eating disorders in non-athlete female students]. J Shahid Sadoughi Uni Med Sci 2012; 20: 322-31. (Persian)

22. Takhshid M A, Ghasemi M. [Methods for assessing insulin sensitivity and resistance]. J Lab Diagnos 2014; 6 : 8-13. (Persian)

23.Bazyar F, Banitalebi E, Amirhosseini SE. [The comparison of two methods of exercise (intense interval training and concurrent resistance- endurance training) on fasting sugar, insulin and insulin resistance in Women with mellitus diabetes]. Armaghane Danesh 2016; 21: 123-34. (Persian)

24. Vizvari E, Farzanegi P, Abbaszadesourati $H$. Effect of vigorous aerobic exercise on serum levels of sirt1 fgf 21 and fetuin a in Women with type II diabetes. Med Lab J2018; 12:1-6 25. Gharadashiafousi A, Gaeini AA, Gholamiborujeni B. [The effect of aerobic interval training on endothelial vasculature function in type 2 diabetes patient]. Iranian J Rehabil Res Nurs 2016; 2: 27-39. (Persian)

26. Bashiri J, Gaeini AA, Hadi H. [Endurance training affects muscular angiogenesis and serum VEGF concentration in diabetic Rats]. Koomesh 2015; 17: 123-32. (Persian)

27. Mahrou M, Gaeini A.A, Javidi M, Chobbineh S. [Changes in stimulating factors of angiogenesis induced by progressive resistance training in diabetic Rats]. Iranian J Diabetes Metab 2014; 14: 1-8. (Persian)

28. Ranjbar K, Nourshahi M, Hedayati M. [Effect of gender and physical activity on serum vascular endothelial growth factor at rest and response to submaximal exercise]. Iran J Endocrinol Metab 2011; 13: 294-300. (Persian) 
29. Sandra J, Gerald F. Watts endothelial dysfunction in diabetes pathogenesis significance and treatment . Rev Diabet Stud 2013;10:133-56.

doi: 10.1900/RDS.2013.10.133

30. Kim J, Montagnani M, Koh KK, Quon MJ. Reciprocal relationships between insulin resistance and endothelial dysfunction: molecular and pathophysiological mechanisms. Circulation 2006; 113: 1888-904. doi:10.1161/circulationaha.105.563213 31. Toloueiazar J , Ravasi AA, Soori R, Akbarnejad A , Hematinafar M. The effect of 8 weeks aerobic training on angiogenesis and angiostatic factors in sedentary
Women. J Urmia Uni Med Sci 2017; 27: 1032-40. (Persian) doi: 10.18869/acadpub.umj.27.12.1032

32.Seida A, Wada J, Kunitomi M, Tsuchiyama Y, Miyatake N, Fujii M, et al. Serum bFGF levels are reduced in Japanese overweight men and restored by a 6-month exercise education. Int J Obes Relat Metab Disord2003; 27: 1325-3. doi:10.1038/sj.ijo.0802408

33.Wang H, Chen Y, Lu X, Liu G, Yan Fu, Luo Y. Endostatin prevents dietary induced obesity by inhibiting adipogenesis and angiogenesis. Diabetes 2015; 64:2442-56 . doi: $10.2337 / \mathrm{db} 14-0528$ 


\title{
Effect of Moderate Aerobic Training on Serum Levels of Angiogenic and Angiostatic Factors in Women with Type 2 Diabetes
}

\author{
Vizvari $E^{l}$, Farzanegi $P^{l^{*}}$, Abbaszadesourati $H^{l}$
}

(Received: January 7, 2018

Accepted: April 21, 2018)

\begin{abstract}
Introduction: One of the consequences of diabetes is an angiogenesis disorder. Physical activity plays an important role in the improvement of this disorder. Therefore, the aim of this study was to investigate the effect of moderate aerobic training on serum levels of angiogenic (NO, VEGF) and angiostatic (ES) factors in women with type 2 diabetes.
\end{abstract}

Materials \& Methods: In this randomized clinical trial with pretest-posttest design, 28 women with type 2 diabetes, age range of 40-50 years, and mean weight of 70.58 \pm 2.11 were randomly assigned into control and exercise groups $(n=14)$. The training intervention included 8 weeks of moderate aerobic exercises (60-70\% HR max) for 60 min each session and 5 times per week. Metabolic parameters and serum levels of NO, VEGF and ES were evaluated before and $48 \mathrm{~h}$ after the exercise protocol. Statistical analysis was performed using repeated measure ANOVA in SPSS software (Version 24) $(\mathrm{P}<0.05)$.
Finding: Eight weeks of aerobic training in women with type 2 diabetes caused a significant increase in NO $(\mathrm{P}=0.09)$, VEGF $(\mathrm{P}=0.014)$, insulin sensitivity $(\mathrm{P}=0.01)$, and HDL $(\mathrm{P}=0.040)$. However, there was no significant increase in $\mathrm{ES}(\mathrm{P}=0.103)$. Moreover a significant decrease was observed in weight, body mass index, fasting blood glucose, triglyceride, $\mathrm{A} 1_{\mathrm{C}}$ $(\mathrm{P}=0.01)$, low density lipoprotein $(\mathrm{P}=0.029)$, and cholesterol $(\mathrm{P}=0.012)$, compared to the control group. Ethics code: IR.IAU.SARI.REC.1396.55. Clinical trial code: IRCT20171104037225N1

Discussion \& Conclusions: Mild regular aerobic exercise seems to have a protective effect against vascular problems due to the improvement of serum levels of angiogenesis and metabolic parameters in patients with type 2 diabetes.

Keywords: Endostatin, Exercise, Lipid profile, Nitric Oxide, Type 2 diabetes, Vascular endothelial growth factor

1. Dept of Exercise Physiology, Faculty of Humanities, Sari Branch, Islamic Azad University, Sari, Iran *Corresponding author Email: parvinfarzanegi@gmail.com 